\title{
Health policy and race equality: an illusion of progress?
}

Allan McNaught PhD

February 2004 saw the report of an inquiry into the case of David 'Rocky' Bennett, an African-Caribbean with schizophrenia, who had died after prolonged physical restraint by mental health nurses. Among its recommendations the inquiry team, led by the retired judge Sir John Blofeld, called on the Government to admit to the presence throughout the National Health Service of 'institutionalized racism'. 'In his response the Secretary of State for Health, John Reid, made no such admission but he did concede that 'there is discrimination in the NHS, both direct and indirect'. Much, indeed, has been published on inequalities within the Service-affecting not only patients but also staff. ${ }^{2}$ How is it that, after two decades of race relations initiatives, the culture of the NHS remains resistant to change on these issues?

Part of the answer may lie in policy process within the NHS. Two key papers in the 1980s examined the balance of power within the Service. Both $\mathrm{Ham}^{3}$ and Hunter ${ }^{4}$ concluded, from study of hospital boards, that managers seeking to do the Government's will often fought a losing battle with the conservatism of the health professions; at that time, government could only guide, not instruct. In addition, Hunter noted that the decision-making process was essentially isolated from lay input.

Since those times the power structure has changed radically. Governments, frustrated by the inertia or recalcitrance of local health authorities and boards, progressively replaced the system of guidance with central mechanisms of 'command and control'. These changes were coupled with efforts to increase public participation, lay membership of health trusts and authorities being reshaped on the lines of non-executive directorships in the private sector. Such attempts at increasing lay involvement cannot, however, be rated a success. Appointments are essentially made on a personal basis, and community health councils have been replaced by a confusing network divorced from community politics or local government; the stress is on individual consumerist 'choice'. The position today is that management has been strengthened but community power remains virtually non-existent. In this paper I argue that the question of 'institutionalized racism' in the NHS has to be viewed in relation to the elites who make policy.

Health Development Department, School of Health \& Social Care, University of Greenwich, Bexley Road, London SE9 2PQ, UK

E-mail: A.G.McNaught@gre.ac.uk

\section{STRUCTURAL INITIATIVES}

An obvious strategy to redress race-based inequalities is to ensure that policy-making bodies reflect diversity in the populations served. Unfortunately, we cannot be sure that an increase in the proportion of lay black and ethnic minority (BME) members will have useful impact on the culture and workings of trusts and authorities. Little has changed since the days of Ham and Hunter, who found that lay representatives of management bodies were not core decision-makers. So, what about recruiting more BME managers and health professionals? Regarding the former, it seems that NHS chief executives at present show scant interest in diversifying their top management teams. ${ }^{5}$ And BME health workers, if they continue to suffer unfair treatment in their employment, are not well placed to champion improvements in standards of care for minority patients.

Few academic studies have been published on race equality and health policy at local level in the NHS. From work done in the early 1980s, Torkington ${ }^{6}$ concluded that racism in the NHS derived from the non-representative nature of senior managers and professionals and the democratic deficit of health authorities. My own research over 1984-1987 indicated that race-related initiatives were attractive to the management of the West Lambeth Health Authority only when financial advantage could be gained by arguing that the greater needs of the ethnic minorities justified a higher level of resources. ${ }^{7}$ The then management team proposed to install ethnic monitoring in the personnel process; that modest development idea has taken some 20 years to be achieved.

\section{PROCESS INITIATIVES}

Improving the approach of clinical and allied services with regard to BME populations is often framed as an issue of cultural awareness. Diversity sessions now feature in most induction programmes. In my view, these initiatives are useless as they fail to make a link between diversity, models of diagnosis, treatment and practice, and the issues of service delivery and social diversity. At its worst, such training is little better than the crude anthropological stereotypes that were popular in the UK in the last century.

Over the past 20 years, the public health community has bristled with studies about the health needs of BME, and 
there is now a substantial body of grounded research on the patterns and distribution of need between and among BME. However, much of this work has not percolated into the management or the clinical domain. Below are three examples of problems at process level.

My first exhibit is taken from 'guidelines for resuscitation of the newborn' adopted by an acute hospital trust in SE London. The policy states:

'A healthy baby will be born blue but will have good tone, will cry within a few seconds of delivery, will have good heart rate (120-150 beats per minute) and will rapidly become pink during the first 90 seconds or so'.

This guideline does not reflect the fact that a significant proportion of babies at the hospital are born to mothers of African or Afro-Caribbean origin. It is therefore hardly appropriate for the population served.

My second exhibit relates to the case of Ingrid Nicholls, 46 , a prospective amputee who was told by her consultant that if she wanted a black artificial foot she would have to buy it privately, and it would cost $£ 3000$. Ms Nicholls was told that her local health authority did not fund black prostheses. She was reported as saying: 'It was an extra shock and blow to my system when I was just coming to terms with losing my foot. With one white foot and one black foot I would have been a laughing stock'. A spokeswoman for the NHS trust which runs the Royal Berkshire Hospital was reported as saying that 'We will be working together with the primary health care trusts to address this issue and clarify funding for future cases'. Meanwhile a spokeswoman for the strategic health authority issued an apology to Ms Nicholls and said the incident had been a misunderstanding, and that 'Any prosthesis she was given would be funded by her local primary care trust and there is no local agreement only to fit white prosthetic limbs. We are talking to all those involved in the care of this patient to clarify matters and reach a satisfactory conclusion' 8

My last exhibit is taken from the Blofeld Inquiry, ${ }^{1}$ which highlighted a 40\% over-representation of black people in the mental health system. The leaked report suggests that this group suffers an excess of misdiagnosis, inappropriate and illegal drug treatment, and punitive management. 15 years have passed since Littlewood and Lipsedge ${ }^{9}$ explored the racist bias that exists in psychiatric theory and diagnosis, and the resulting inadequacy in treatments.

\section{CONCLUSIONS}

The NHS is a centralized professional bureaucracy, with policy driven by the Department of Health and Ministers.
This centralization has been achieved through strengthening of the management cadre. Local communities and lay representatives still have little power to influence health policies. There is no denying that there have been some important symbolic changes in the nature of the discourse on race and health policy, and a welcome diversification of the membership of NHS policymaking bodies. However, improvement at process level has been slow. One reason is that schools of medicine, health and social care have largely failed to develop appropriate models for medical and healthcare practice in a diverse society. Nor, within the NHS, do we have an enlightened approach to development of clinical practice and related standards. Quite modest steps would make current services more competent in meeting the needs of BME people. It is suggested that, in day-to-day practice, health professionals need to keep in mind the simple question 'How does this apply to BME?' Beyond this, I suggest that clinical units should:

- Draw on the experience and knowledge of BME/ international staff in a more structured way to review clinical procedures and policies

- Ensure that procedures and practices are evidencebased. Where evidence is slim, units should do their own small-scale research-for which an effective system of ethnic monitoring is essential

- BME community groups and patients know much about the services and their failings and their views deserve sympathetic attention from NHS managers and clinicians.

The centralization and concentration of power in the hands of a small homogeneous white male policy elite, at local and national level, is in itself a problem. The culture and worldview of this group dominates the NHS. The NHS Chief Executive has launched a 'BME Leadership Programme', but the danger is that it will lapse in the manner of such efforts in the late 1970s and 1980s. The designers of the current initiative might usefully have looked into what factors affect BME progress and retention in the NHS.

The unifying narrative behind all stories of 'men behaving badly' is the nature of political control and the related performance management regime. Until the late 1980s, Health Service managers strove to mark themselves out as a profession with their own qualification and identity. Much of that has collapsed, as they have joined the larger Civil Service. Meanwhile, the NHS supports a culture that has strong continuities with the past, including discrimination against BME patients and staff. Several reports indicate that it is a world characterized by macho posturing, bullying and unfair treatment. ${ }^{10-12} \mathrm{~A}$ shift in operating culture, 
values and practices an essential part of a race equality strategy.

It may be useful to sketch out the characteristics of an NHS that integrates racial equality as a core value, and part of its processes and priorities. First, the kind of unprofessional events highlighted in my three examples would be exceptional. Clinical practitioners would incorporate ethnic differences into their operating paradigms. Secondly, policy-makers would see BME communities and their organizations as partners rather than unwelcome critics. Most BME discontent with the NHS is generated by a combination of inattention to customer relations, poor and inappropriate treatment, and hostility to suggestions for change. Working with communities is a messy business which requires creativity, patience and a real understanding of other citizens. The final point relates to the overt and covert management culture of the NHS. Diversification of the membership of the management and the policy elite is a welcome change but the priorities and values of this elite must also change if the reform is to be other than symbolic. Those who wish the NHS to succeed have no option but to fight for and promote humanistic values, to which racial equality is intrinsic.

\section{REFERENCES}

1 Bennett Inquiry Report [www.nscstha.nhs.uk/11516/David\%20 Bennett\%20Inquiry.pdf]

2 Sheikh A. What's to be done about racism in medicine? I $R$ Soc Med 2001;94:499-500

3 Ham C. Policy Making in the NHS: A Case Study of the Leeds Regional Hospital Board. London: Macmillan, 1981

4 Hunter D. Coping with Uncertainty: Policy and Politics in the NHS Chichester: Research Studies Press, 1983

5 Managers short on BME policies [News]. Health Serv J 2004;114(5892)

6 Torkington P. The Racial Politics of Health: A Liverpool Profile. Liverpool: Merseyside Area Profile Group, 1983

7 McNaught A. Race and Health Policy. London: Croom Helm, 1988

8 Vasagar J. NHS apologises for 'white-only' false foot error: Black patient told she must pay for matching limb. The Guardian 26 August 2003

9 Littlewood R, Lipsedge M. Alien \& Alienist: Ethnic Minorities and Psychiatry. London: Taylor and Francis, 1989

10 Carlisle D. Off the fair way: were middle managers denied voluntary redundancy in the fall out from Shifting the Balance, while top executives trousered six-figure pay-offs? Health Serv J, 5 December 2002

11 Donnelly L. When a trust chief exec came to blows with her SHA, something had to give. Health Serv J, 20 May 2004

12 Greenwood L. Pain into gain: the fall out from the implementation of Shifting the Balance was the displacement of hundreds of dedicated NHS staff and the threat of job losses. But help is out there. Health Serv J, 10 October 2002 